Orbis Tertius, vol. XXII, $n^{\circ}$ 26, e051, diciembre 2017. ISSN 1851-7811

Universidad Nacional de La Plata

Facultad de Humanidades y Ciencias de la Educación

Centro de Estudios de Teoría y Crítica Literaria

\title{
Creencias y supersticiones en conflicto: visiones de la religiosidad popular en la Argentina de entresiglos
}

\author{
Alejandra Mailhe * \\ * Universidad Nacional de La Plata, Argentina.
}

\section{PALABRAS CLAVE}

Positivismo / antipositivismo

Argentina

Entresiglos

Religiosidad popular

Revistas científicas

\section{KEYWORDS}

Positivism / Antipositivism

Argentina

19th century

20th century

Popular religiosity

Scientific journals

\section{RESUMEN}

Este artículo explora la patologización de las creencias populares en la Argentina de entresiglos. Considera esta conceptualización como parte de un proceso más amplio de control social, que incluye la identificación del "otro" con lo inconsciente. Para ello, aborda ensayos y artículos aparecidos entre las décadas de 1880 y 1910. En estos textos, el fanatismo católico, los movimientos milenaristas, el curanderismo o la hechicería popular revelan inquietantes puntos de contacto con la histeria femenina, y con otras formas de patología individual y colectiva. Además, este trabajo considera el modo en que el espiritualismo se vuelca sobre la misma religiosidad popular, polemizando con el positivismo en su interpretación.
ABSTRACT
This article explores the pathologization of popular beliefs in Argentina, at the turn of the of 19th century. It studies pathologization as part of a wider process of social control that fostered the identification of the "other" with the unconscious. For that, it analyses essays and articles that were published between the decades of 1880 and 1910. In these texts, catholic fanaticism, millenarian movements, quackery or popular sorcery, all reveal disturbing contact points with female hysteria, and with others forms of individual and collective pathology. Finally, this work analyses the way in which spiritualism approaches popular religiosity in a reading that puts into question former positivist interpretations.

Cita sugerida: Mailhe, A. (2017). Creencias y supersticiones en conflicto: visiones de la religiosidad popular en la Argentina de entresiglos. Orbis Tertius, 22(26), e051. https://doi.org/10.24215/18517811e051 
A principios del siglo $\mathrm{XX}$, el estudio de las religiosidades y de las prácticas médicas populares constituye una zona de disputa especialmente álgida tanto en el positivismo hegemónico como en el incipiente folclorismo criollista. Entre la medicalización de los sectores populares y el registro nostálgico de "curiosidades en extinción”, los intelectuales (especialmente médicos psiquiatras y criminólogos, además de antropólogos e historiadores, tensionados entre la práctica amateur y la profesionalización disciplinar) se vuelcan al registro, análisis -y eventualmente represión- de prácticas populares vinculadas tanto al curanderismo como a los ritos y los mesianismos “residuales”, productos de un universo de valores “retrógrados”, “pre-modernos” y "resistentes a la secularización”.

Este trabajo analiza algunos artículos, informes y ensayos publicados en Argentina entre 1880 y 1910 (en el cruce entre psiquiatría, psicología de las multitudes y antropología), y centrados en el análisis "científico" de diversas manifestaciones religiosas de la "irracionalidad" popular. Para ello, considera textos aparecidos en prestigiosas revistas científicas de Buenos Aires, así como también algunos ensayos que polemizan parcialmente con el positivismo hegemónico. En este corpus, los movimientos milenaristas, el curanderismo, la hechicería popular o el fanatismo católico revelan inquietantes puntos de contacto con la histeria femenina, con otras formas de la patología individual, con la caída en "estado de multitud" de las nuevas masas, y con el fanatismo político. En definitiva, nuestra lectura apunta a reconstruir la gradación etnocéntrica que organiza la sugestionabilidad de los sectores populares, al insistir en diagnosticar, para estos grupos, un predominio de la irracionalidad que a menudo deviene síntoma de su supuesta inmadurez cultural y/o política.

\section{Supersticiones y fanatismos bajo la lente médica}

Las principales revistas médicas editadas en Buenos Aires en esta etapa publican trabajos centrados en el agravamiento de las enfermedades mentales por la influencia negativa del curanderismo y de las religiosidades populares en general, al tiempo que denuncian la competencia entre curanderismo y ciencia médica por el dominio de las enfermedades físicas y mentales. $\underline{1}$

En efecto, en esta psiquiatrización de las prácticas ajenas a la tradición médica, el curanderismo es reprimido por su peligrosidad, pero también porque le disputa a la ciencia el dominio de la sugestión y de la cura. La represión, más dura a partir de entresiglos, se manifiesta en las leyes que penan el ejercicio ilegal de la medicina, en la vigilancia ejercida sobre los curanderos, e incluso -en algunos casos- en su detención en cárceles o asilos psiquiátricos. A menudo los artículos dan cuenta de esta preocupación por reprimir el ejercicio ilegal de la medicina, abogando por reformas legales o por el cumplimiento de las leyes existentes. En varios textos los autores se quejan de las dificultades para lidiar con el curanderismo, extendido especialmente en el interior de la provincia de Buenos Aires. $\underline{2}$

Solo por citar un ejemplo, la Revista Médico-Quirúrgica edita, en 1885, una nota del médico Franceschi en la que éste denuncia el predominio del curanderismo en la región. Según este facultativo, en el pueblo de 9 de Julio y en sus aledaños, la población acude a los curanderos pero nadie visita al médico (e incluso, durante una terrible epidemia de viruela, declara haber asistido apenas a dos personas... iporque la enorme mayoría solo acudió a su consultorio para pedir los certificados de defunción de sus parientes!).

En numerosos textos, el curandero aparece como un charlatán embaucador y/o como un enfermo mental (en cualquier caso, como analogon de lo que Gustave Le Bon define en su Psychologie des Foules de 1895 como meneur), en un discurso que busca imponer la medicina científica y patologizar la medicina popular, en el marco de un proceso más amplio de control de las culturas populares. ${ }^{3}$

Aunque el tema de la religiosidad popular gravita en las revistas científicas consideradas, lo hace con un peso realmente menor si se lo compara con la centralidad que adquiere en las publicaciones de otros contextos latinoamericanos como los de Brasil, Cuba o Perú. En contraste con los diagnósticos alarmantes, extendidos en esos países (dada la vitalidad allí de diversos sincretismos religiosos), las revistas porteñas identifican más bien 
casos aislados, que no trascienden hacia la experiencia colectiva del "contagio", y que remiten al catolicismo (aun en sus versiones híbridas), y no a otras experiencias religiosas menos occidentales.

En las revistas porteñas aquí consideradas, varios informes señalan que las creencias supersticiosas y el fanatismo religioso -aun en su vertiente católica- juegan un papel importante en la sugestión negativa de los pacientes con histeria u otras patologías mentales, e incluso subrayan el modo en que las prácticas religiosas empeoran el estado mental de los "vesánicos". Por eso numerosos textos condenan el fanatismo católico, desde una secularización cientificista en la que también resuenan los ecos del anti-hispanismo, heredado de las primeras décadas del siglo XIX, y aun activo.

Así por ejemplo, en "Monomanía religiosa” (artículo editado en la Revista Médico- Quirúrgica en 1883), Lucio Meléndez aborda el caso de Tomás $\mathrm{K}$, un inmigrante irlandés, ferviente católico con una monomanía religiosa en base a la cual se identifica con Jesús, al punto de interrumpir una ceremonia religiosa para retirar la corona de Cristo y auto-coronarse como su sucesor. Recluido en el Hospicio de las Mercedes, el paciente acaba suicidándose ante el primer descuido médico. A partir de este caso, Meléndez sentencia que "las prácticas religiosas no ejercen influencia alguna favorable en el tratamiento de los vesánicos, empleadas aquellas como medios curativos” (Meléndez 1883: 174). Además, el autor aprovecha este caso para condenar la inmigración (al menos aquella que, como la irlandesa, se halla -supuestamente- marcada por el fanatismo religioso). $\stackrel{4}{4}$

Este tipo de condenas ligadas a la inmigración se percibe en otros textos del período. En "Los locos en la Capital" (artículo publicado en la Revista Médico-Quirúrgica en 1884), Meléndez analiza el aumento en el número de enfermos mentales en Buenos Aires, poniendo especial énfasis en los casos de delirio religioso; los atribuye no solo al crecimiento de la ciudad, $\underline{5}$ sino también a la inmigración, en base a factores diversos (desde la herencia biológica hasta la inestabilidad económica) que hacen que "gran número de insanos pasen de los navíos al Hospicio de las Mercedes” (Revista Médico-Quirúrgica 1884: 103).

Numerosos trabajos insisten en responsabilizar al catolicismo, al menos en parte, por el agravamiento de las dolencias mentales. Así por ejemplo en "Melancolía apática...” (texto editado en la Revista Médico-Quirúrgica en 1885), Meléndez aborda el caso de Doña N.N., víctima de una "neurosis de la inteligencia” suscitada por su temperamento nervioso, sumado a una meningitis padecida en la juventud. Entre los factores desencadenantes de su crisis, juega un papel clave el confesor de la paciente, que en lugar de aliviarla de preocupaciones, ha contribuido a romper su equilibrio mental, incentivando su sentimiento de culpa hasta hacerla "sentir una voz interior que le ordenaba hacer penitencia con el objetivo de salvarse” (Meléndez 1885: 190). Por ende, entre otros recursos, Meléndez acude a la intervención de un sacerdote, para contra-sugestionar positivamente a la paciente, convenciéndola de haber alcanzado ya la anhelada redención espiritual. Como en los artículos arriba mencionados, también aquí el autor remata el informe con una dura advertencia acerca de la influencia nefasta que ejerce el fanatismo religioso sobre la salud mental de las personas nerviosas. $\underline{6}$

De hecho, varios trabajos muestran más claramente la convergencia entre histerización del sujeto femenino y patologización de la religiosidad popular. En "Curanderismo y locura", editado en Archivos... en 1903, los médicos N. Acuña y J. Alba Carreras abordan el diagnóstico de M. G. (conocida como la "Hermana María”), una mujer católica, por entonces famosa curandera popular, dedicada a la sanación de enfermedades mentales, en base al reconocimiento de los pecados por parte de sus pacientes. El informe deja entrever la fuerza de la secularización científica arrasando la religiosidad popular. Los médicos diagnostican histeria, empleando ese diagnóstico como sanción al desvío religioso. Lo que molesta de esta ciudadana "ejemplar" es tanto el exceso de religiosidad (solo conceptualizable como síntoma de degeneración), como su actitud desafiante frente a la psiquiatría, a la cual enfrenta disputándole precisamente el dominio de la enfermedad mental. El caso de M. G. permite recrear la perduración, en plena ciudad modernizada, de resabios retrógrados de la antigua y extendida histeria religiosa.

Además, los discursos de la criminología positivista refuerzan la colocación del curanderismo -y de las religiosidades populares en general- en las fronteras del delito, además de en los límites de la patología mental. 
Así por ejemplo, el abogado Eusebio Gómez, en su libro La mala vida en Buenos Aires (editado en 1908), sitúa a curanderos y adivinos en el mismo magma de la "mala vida" al que pertenecen prostitutas, homosexuales, mendigos y estafadores de diverso tipo. Basándose en Archivos... entre otras fuentes, ${ }^{7}$ esa población (situada en los márgenes de las ciudades y en los límites de la legalidad) es abiertamente concebida como patológica y/o al menos como potencialmente peligrosa. ${ }^{-}$Además, Gómez prolonga el anti-catolicismo médico visible en los otros informes pues, considerando en un mismo nivel a frailes, monjas, adivinas y curanderos, define a todos estos "religiosos” como parásitos improductivos y estafadores.

Intentando cierta reivindicación del margen propio en contraste con el delito extranjero, algunos textos rescatan al "curandero criollo", al concebirlo como una figura negativa, pero también como un reservorio de la memoria popular local $\underline{\underline{9}}$ en contraste con los esoterismos foráneos. Así por ejemplo, en "Factores científicos del charlatanismo" (editado en La Semana Médica en 1910), Leónidas Facio confirma la validez científica de la sugestión, al recordar con nostalgia el poder sugestivo de Francisco Sierra, un famoso curandero criollo, presentado como un anciano venerable, arquetipo de la cura "saludable" por sugestión, en contraste con los charlatanes extranjeros, ávidos de lucro, que se promocionan en los periódicos de la capital. $\stackrel{10}{ }$ Casi diez años después de su muerte, Sierra (conocido como "el médico del agua", muy popular y éticamente elevado por su sinceridad frente a los casos y por su desinterés material) adquiere la dimensión de una figura auténtica de la historia local, erigiéndose en símbolo de la antigua convivencia pacífica entre medicina popular y ciencia médica, ahora imposible por el auge del positivismo.

Sin embargo, esta defensa nacionalista del curandero criollo es muy limitada en el discurso positivista, tanto por la condena taxativa de las religiosidades populares en general, como por el sentimiento de amenaza -aún presentefrente a ciertos rebrotes "atávicos" del mesianismo local. En este último sentido, cabe recordar que, en entresiglos, todavía está vivo el recuerdo de la matanza de Tandil, ocurrida en enero de 1872, cuando un grupo de 50 gauchos, recuperando consignas y emblemas del rosismo (como la divisa punzó), son probablemente impulsados por el curandero Jerónimo de Solané o “Tata Dios”, para asesinar a 36 inmigrantes (en su mayoría, italianos y vascos), por considerar a los extranjeros como "gringos francmasones" que amenazan la religión y los derechos del pueblo criollo. $\underline{11}$ El caso (legible poco después, a partir de la psicología de las multitudes) parece confirmar el riesgo al contagio colectivo por sugestión y -peor aún- el peligroso poder sugestivo del curandero, incluso como potencial líder de una rebelión colectiva. $\underline{12}$

La patologización de las religiosidades populares, visible en estos artículos científicos, se despliega en el marco de una más amplia patologización de las prácticas culturales de los sectores populares y del margen social. Tal como puede entreverse en los casos arriba mencionados, la mirada cientificista está plagada de diagnósticos en los que se cruza la dominación de clase, de raza y de género, incluyendo diversos mecanismos de distinción tendientes a deslegitimar a las alteridades sociales. Algunos trabajos incluso estigmatizan en bloque a ciertos grupos sociales, patologizando abiertamente la mera condición de clase. $\underline{13}$

Además, la lectura de estas fuentes revela que, para los psiquiatras y criminólogos argentinos, fuertemente secularizadores y anticlericales, el modelo ideal de clase baja debe presentar apenas una religiosidad moderada, ya que todo fanatismo religioso es condenado negativamente como una superstición antimoderna que puede transformarse fácilmente en peligrosa enfermedad mental. Las formas religiosas mesiánicas, "pre-políticas”, de fanatismos colectivos (como aquel que desencadena la masacre de Tandil) se presentan en Argentina (junto con las viejas montoneras y los malones acallados por la llamada "Campaña al Desierto") como parte de una irracionalidad de masas en proceso de superación... aun cuando el carácter pretendidamente universal y transhistórico de lo irracional impida someter esas manifestaciones a una escala evolutiva.

Tal como puede verse en estos casos, al no visualizar en Argentina religiosidades populares resistes a la occidentalización (probablemente como resultado del propio eurocentrismo letrado, que se concentra en las masas inmigrantes de la capital, invisibilizando el resto del país), la mayoría de los criminólogos argentinos avanza en 
una crítica muy virulenta contra el catolicismo (que se alimenta del profundo anti-hispanismo decimonónico), patologizando el fanatismo católico de los inmigrantes, el misticismo popular de base criolla o la educación católica tradicional, entre otros elementos (en contraste con autores latinoamericanos como el brasileño Nina Rodrigues o el cubano Fernando Ortiz, que enfrentan la vitalidad innegable de las religiosidades afro-americanas, de la cultura negra en general y de otros misticismos milenaristas y “retrógrados”).

\section{¿Supersticiones para frenar el materialismo?}

Ahora bien; esta patologización de las culturas populares se consolida como discurso hegemónico precisamente cuando emergen algunos estudios sobre las prácticas curativas de indios, negros y gauchos, dando lugar a una nueva disciplina, la antropología médica. Esta disciplina surge desgarrada ab origine por una tensión ideológica y epistemológica interna, entre la antropología positivista que aspira a la represión de los saberes populares, y el nacionalismo cultural dispuesto a recuperar -aunque de forma controlada- la dimensión indo-hispánica de la identidad, como respuesta ante el avance del "aluvión inmigratorio".

La ambivalencia entre la adhesión al positivismo hegemónico y cierta legitimación marginal de los saberes populares se despliega también en el seno del ensayo de interpretación vinculado al espiritualismo antipositivista. Las contradicciones anidan a menudo en el interior de un mismo discurso, poniendo en evidencia las dificultades que supone un cambio de paradigma o -en otros términos- los efectos centrípetos de la hegemonía discursiva, en el sentido de Angenot (2010).

El libro titulado Reseña histórico-descriptiva de antiguas y modernas supersticiones del Río de la Plata, editado en 1896 por el filólogo hispano-uruguayo Daniel Granada, lleva esta ambigüedad hasta la exasperación, centrándose además en la misma religiosidad popular condenada por las revistas científicas arriba mencionadas. Algo semejante ocurre en el ensayo "Las supersticiones nacionales", editado por el psiquiatra y filósofo bergsoniano Alejandro Korn en los Anales de psicología de 1911. Veamos.

Granada advierte que su libro busca recuperar la dimensión espiritual (o la "verdad estética” del hombre), para frenar la secularización del materialismo positivista que reprime todo elemento sobrenatural. Para ello, realiza un rescate erudito de las creencias populares, abordando un amplio corpus de prácticas curativas vinculadas al curanderismo y la magia en el Río de La Plata. Granada decide centrarse en este campo precisamente porque éste se ha convertido en el principal punto de convergencia -y de disputa- entre la psicología experimental y las doctrinas esotéricas: "fisiólogos, médicos, físicos, filósofos y hombres de letras, en el Antiguo y en el Nuevo Mundo" (Granada, 1947: 10) se vuelcan obsesivamente sobre los mismos "fenómenos preternaturales" (las apariciones, la posesión, las curas mágicas y otras manifestaciones psíquicas), convertidos ahora en un objeto de estudio privilegiado.

También Korn, en un ensayo de 1911, inscribe deliberadamente su reflexión sobre las supersticiones en el marco del interés contemporáneo por el "sentimiento místico", dejando entrever así el modo en que su intervención espiritualista busca establecer un contrapunto con respecto a las perspectivas dominantes en el cientificismo positivista, alejándose al menos a priori de la patologización de las creencias arriba considerada. En efecto, para Korn las supersticiones vulgares, la religión y la filosofía constituyen manifestaciones diversas de la misma "sed metafísica” inherente a la condición humana.

Reconociendo la competencia (pero también, en algunos casos, la colaboración) entre los saberes populares y la medicina científica, $\underline{14}$ Granada busca organizar el continuum de las supersticiones, separando los fenómenos explicables en términos científicos, de las meras creencias resultado de la ignorancia popular o de la sugestión colectiva. Así por ejemplo, demuestra los efectos alucinógenos de ciertas hierbas y las causas físico-químicas de la "luz mala"; confirma la licantropía pero la redefine como "psicopatología”, o advierte que la sugestión y la hipnosis -a las que apelan el curanderismo y las religiosidades populares- han sido científicamente comprobadas por Jean-Martin Charcot. Granada estudia la creencia en la posesión o las técnicas de curación bajo hipnosis por parte de hechiceros, adivinos, sacerdotes y magos, comparándolas con las formas actuales de curación de la 
histeria. De este modo, vuelve evidente en qué medida la sugestión (y especialmente la hipnosis) se han vuelto objetos privilegiados por su centralidad tanto en las medicinas populares como en las exploraciones psiquiátricas contemporáneas. Y tomando partido en ese debate interpretativo, asume siempre el punto de vista de la ciencia médica, insistiendo en que el curandero solo puede curar a los auto-sugestionados, en general bajo cuadros de histeria..$\underline{15}$

También el ensayo "Las supersticiones nacionales" adhiere implícitamente al positivismo, aunque el autor se esfuerce por subrayar el lazo entre creencias supersticiosas y "sed de trascendencia". Así por ejemplo, reactualizando un típico clisé evolucionista, señala que estas creencias son "fósiles mentales" equivalentes a “restos paleontológicos” (Korn 1911: 288). Y si la medicina popular contiene concepciones "científicas” del pasado ya residuales, su supervivencia vuelve evidente en qué medida la sociedad está constituida por capas superpuestas con grados diversos de maduración intelectual. $\underline{16}$

Profundizando su objetivo instrumental de reafirmar las jerarquías culturales, Granada refuta sistemáticamente las creencias rudimentarias del "vulgo". Sin embargo, también reconstruye con detalle los argumentos de los espiritismos contemporáneos más sofisticados -es decir, de los cultos más cultos- cuya proximidad respecto de la ciencia médica los vuelve más problemáticos. En este sentido, despliega los principales argumentos del ocultismo francés, confrontándolos con la ciencia contemporánea, aunque también aquí termina volviéndose, en general, en favor de esta última. Así por ejemplo, frente a las apariciones, revisa tesis contemporáneas que buscan una explicación racional del fenómeno, pero las descarta como científicamente inaceptables, o analiza la tentativa cientificista de M. A. de Rochás en L’Exteriorisation de la Sensibilité, de probar empíricamente la acción a distancia -por medio de muñecos, ropa o fotografías que actuarían sobre la sensibilidad exterior del paciente-, tendiendo a adoptar también frente a este fenómeno una posición escéptica. $\frac{17}{17}$

En este sentido, la dimensión esotérica de las creencias populares - aquello que la racionalidad científica descartase convierte literalmente en un elemento residual, prueba de un universo cultural en extinción que debe ser

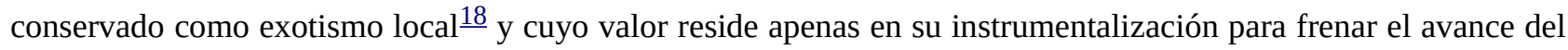
materialismo... y del ateísmo. Así, aceptando la explicación científica contra el "vulgo”, pero también aceptando la explicación esotérica contra los positivismos, $\frac{19}{}$ Granada diseña un doble discurso según el tipo de interpelación, deslegitimando las creencias populares cuando el agonista es el sujeto popular (su propio objeto de estudio), $\underline{\underline{20}}$ y legitimándolas cuando el agonista es el propio mundo letrado en el seno del cual se juega su confrontación con el positivismo. De este modo, neutraliza el "reencantamiento del mundo" al que aspira a priori en su cruzada antipositivista.

Las ambivalencias de Granada frente a los fenómenos "preternaturales” que estudia repercuten en su posición con respecto a la existencia del espíritu, un problema central en el debate filosófico entre la psicología experimental y el espiritualismo: citando La Science de l'Âme dans les Limits de l'Observation del krausista belga Guillaume Tiberghien, y a partir de los fenómenos de alucinación narcótica y de hipnosis, plantea el problema del enlace “íntimo" entre el espíritu y el sistema nervioso "cerebro-espinal”, como "la clave antropológica de todos los fenómenos sensitivos de la naturaleza humana” (Granada 1947: 384), apuntando a superar los límites dogmáticos del positivismo. Tanto esta perspectiva sobre el problema del espíritu, como la apelación a las creencias como vía de compensación metafísica (ante el avance arrasador del materialismo) revelan la simpatía de Granada con el krausismo dominante en el campo intelectual español de esta etapa.

Ahora bien; ¿por qué vías esos esoterismos residuales podrían frenar -o al menos espiritualizar- el materialismo, si ambos autores los desacralizan, confirmando su ilegitimidad científica...? Si la explicación científica arrasa con la magia, el folclore centrado en la magia permite preservar un halo de espiritualidad, aunque ya despojado de todo espiritismo. Si el positivismo descalifica la religión y las aspiraciones trascendentes del pueblo, considerándolas elementos foráneos y retrógrados, el antipositivismo de Granada responde recreando un rico acervo de tradiciones esotéricas, aunque éstas se encuentren a punto de extinguirse. Caída el aura de lo 
sobrenatural, ese museo de creencias ya secularizadas deviene ahora una cantera de motivos disponibles para la literatura y el arte, que precisan de la religión para frenar el avance arrasador del realismo (realismo que, en el campo estético, equivale al arrasamiento materialista en general; Granada, 1947: 12). $\underline{21}$ En esta dirección, Granada seculariza explícitamente las supersticiones populares, pero para reubicarlas bajo la sacralidad moderna del arte, confirmándolas como vías válidas para espiritualizar la experiencia moderna, sin resistirse a ésta sino acompañándola, mediante un reequilibrio de fuerzas en base a la recuperación de la metafísica.

En este sentido, el gesto de Granada -confirmado luego por el de Korn- anticipa el folclorismo esotérico de Ricardo Rojas en su ensayo Eurindia de 1922;르 establece puntos de contacto con el esoterismo helenizante de Leopoldo Lugones en El payador de 1916, e incluso abre camino al retorno fascinado a la religiosidad popular, como fuente de inspiración estética, entre las vanguardias primitivistas (pues aun cuando en los años veinte el primitivismo vanguardista postule una ruptura radical con los espiritualismos de entresiglos -condenando la larga genealogía que patologiza las religiosidades populares, o subrayando su identificación con las vías esotéricas de reconexión con lo inconsciente-, perdurará la ambivalencia letrada -que ya se percibe en germen, en el ensayo de Granada, oscilando entre la secularización y la resacralización estetizante de ese sustrato-). $\underline{23}$

Además, para Granada, frente a la secularización internacionalista del positivismo, $\underline{24}$ el esoterismo folclórico permite mantener vivo el lazo con la tradición cultural hispano-indígena. En efecto, anticipando el nacionalismo cultural de Rojas, y a diferencia del enfoque de Korn (poco inclinado a subrayar el potencial nacionalista contenido en las supersticiones), $\underline{25}$ para Granada el mundo del esoterismo se revela como un mosaico de sustratos culturales yuxtapuestos desde donde América religa con España primero, y luego -a través de España- con el mundo judío, moro, hindú, persa, gitano y grecolatino, en base a la identidad de los fenómenos "preternaturales" (y en definitiva, en base a la universalidad del espíritu humano). Esa universalidad (nuevamente afín al krausismo) duplica e invierte el universalismo cientificista y modernizador del positivismo, porque garantiza el acceso al cosmopolitismo por la vía del espíritu y de la tradición, y bajo el control de un ethos mestizo (hispano-indígena) como base. En este sentido, el antipositivismo de Granada puede verse como prefiguración "noventaiochista" del arielismo, y como germen del telurismo culturalista de figuras como Rojas.

En la formulación de esa teoría del mestizaje juegan un papel privilegiado doctrinas esotéricas como la Histoire de la Magie de Elifás Leví, o el Traité Méthodique de Science Oculte de Papús, tal como sucede en el caso de Rojas con el ocultismo de masas difundido por Edouard Schuré. $\underline{26}$ Para Granada, se trata de discursos que articulan diversos ocultismos (incluyendo el magnetismo, el neopitagorismo y el espiritismo); que refuerzan la identificación entre los fenómenos abordados desde la Antigüedad hasta el presente (en base a la manifestación de un solo ideal espiritual, y una visión sincrética del cosmos o del progreso del espíritu), y que incluso teorizan sobre la transmigración de las almas, en base a una dinámica teóricamente homóloga a la del mestizaje cultural.

Mientras Granada jerarquiza las viejas supersticiones criollas y el esoterismo europeo contemporáneo, pero también los integra para explorar sus puntos de contacto, Korn en cambio opta por aislar un conjunto acotado de fenómenos populares, sin establecer puentes con los “equivalentes mentales” de los ocultismos que alcanzan a las elites, reforzando así la asincronía evolutiva de este sustrato cultural.

A la vez, adhiriendo al punto de vista hegemónico en la psiquiatría contemporánea (en un gesto que neutraliza su voluntad inicial de revalorizar las creencias como parte de una metafísica espontánea), señala el papel riesgoso de las supersticiones y creencias en el agravamiento de las enfermedades mentales, y defiende la importancia de la pericia psiquiátrica para diagnosticar patologías mentales en los casos en donde el vulgo identifica "daños".

También Granada realiza diversas operaciones de reduccionismo eurocéntrico, insistiendo en la convergencia entre culturas a fuerza de negar diferencias insoslayables (por ejemplo entre indígenas y europeos, o entre grupos indígenas entre sí). $\underline{\underline{27}}$ Ese tipo de reduccionismos lleva implícito además el desconocimiento de la lucha por la dominación material y simbólica, así como también el olvido de la violencia en base a la cual se forjaron los 
diversos sincretismos coloniales $\underline{28}$ (solo al comentar La Sorcière de J. Michelet, reconoce que hay lecturas que, en el presente, subrayan la dimensión política de la brujería como resistencia "de los oprimidos [...] contra las crueles injusticias y odiosas tiranías de clérigos y señores”; Granada 1947: 390).

Además, la Reseña... está sobrecargada de referencias a la literatura colonial hispánica, pues Granada no se basa en informantes sino en la relectura de fuentes eruditas de cronistas coloniales, e incluso en confesiones sustraídas bajo tortura, en el marco de los procesos inquisitoriales, ahora leídas como documentos "transparentes" capaces de "reflejar" las creencias populares. $\underline{\underline{29}}$ En cambio Korn, prescindiendo de las fuentes coloniales, se basa exclusivamente en la Reseña... de Granada y en textos del etnógrafo Juan Bautista Ambrosetti, $\underline{30}$ evidenciando así su afiliación a figuras distantes respecto del positivismo. $\underline{\underline{31}}$

En el caso de Granada, además, bajo la reivindicación de esa espiritualidad trascendente parece anidar, solapada, la nostalgia del imperialismo cultural hispánico: a la crisis económica y política de España -precisamente en el contexto de quiebre del colonialismo español-, Granada opone la "riqueza simbólica” del ethos indo-hispánico. Y ese gesto -clave en el pensamiento de la generación del 98'- será fundamental en la relegitimación regionalista conservadora, emprendida en las primeras décadas del siglo XX.

En cada detalle, el ensayo de Granada perfila la construcción de una argumentación antipositivista, a priori opuesta a la de los intelectuales nucleados en torno a las revistas científicas: el arte y la religión se re-ubican por encima de la ciencia; el positivismo se deslegitima como ajeno al ethos hispano-indígena; el realismo -en tanto materialismo- es condenado como tendencia contraria a la trascendencia espiritual a la que debe aspirar el arte, y el esoterismo popular es instrumentalizado como cantera de religiosidades capaces de frenar la desacralización del mundo desatada con la modernización. Contradictorio -reiterando la tensión entre el rechazo del positivismo y el rechazo de las supersticiones-, Granada recrea el universo de las creencias y a la vez confirma la censura que debe aplicarse sobre este universo de valores, aunque reclame que esa censura sea "indulgente" e indirecta, para evitar una reacción defensiva del "vulgo" frente a las críticas.

Del mismo modo, el breve ensayo de Korn deja entrever la tensión que atraviesa su obra (entre filosofía neokantiana y cientificismo médico) al oscilar entre la valoración antipositivista de las supersticiones (como prueba de la dimensión metafísica inherente a la naturaleza humana), y la condena de las mismas en base a los principales tópicos de la patologización psiquiátrica (al afirmar la falsedad de los saberes populares referidos a los fenómenos mentales, y al denunciar el peligro de que las dolencias se agraven en base a la sugestión producida por las supersticiones y por el fanatismo).

En el caso de Granada, la fuerza centrípeta de la hegemonía discursiva que ejerce el positivismo se replica en otros planos del ensayo. Por ejemplo, en el campo del arte, el autor de la Reseña... adopta un punto de vista moralizante que, más allá de su rechazo del realismo, converge con el criterio paternalista de José Ingenieros (y de Archivos... en general) acerca del papel didáctico que debe asumir la literatura de masas para promover la elevación ética del pueblo, en oposición a la peligrosa difusión del delito que estimula la literatura criollista en general. $\underline{32}$

\section{Breves consideraciones finales}

Tanto los autores vinculados al cientificismo positivista como aquellos inclinados a cuestionar el positivismo tienden a volcarse sobre los mismos fenómenos de la religiosidad popular. El interés por estas prácticas aumenta junto con el crecimiento de la psiquiatría positivista y de las doctrinas esotéricas. Explorando el diálogo entre ambas, algunos autores críticos del positivismo buscan compensar el materialismo cientificista con el retorno de la trascendencia espiritual en términos religiosos, espiritistas y/o espirituales en sentido amplio.

Pero si las revistas científicas arriba consideradas demuestran la supervivencia de casos muy aislados de misticismo retrógrado, figuras como Granada, por el contrario, despliegan una geografía simbólica del Río de la Plata cargada de esoterismos vivos en el presente, que relativizan el éxito de la modernidad, abriendo vasos 
comunicantes con la Europa ocultista, con el mundo hispano-colonial, e incluso -a través de éste-, con Oriente y con África, como contra-cara de la psiquiatría positivista y del internacionalismo modernizador... aunque este gesto esté lejos de implicar una legitimación neo-romántica o culturalista de esas periferias.

Más allá de estas diferencias, la hegemonía discursiva ejercida por el cientificismo puede percibirse no solo en la convergencia de los diversos diagnósticos médicos que patologizan las religiosidades populares, sino también en la enunciación ambivalente que despliegan las voces críticas del positivismo en esta etapa, al oscilar entre el rechazo del positivismo y el rechazo de las supersticiones, desde un punto de vista evolucionista y etnocéntrico... en definitiva, afín al cientificismo.

\section{NOTAS}

1 Algunos casos mencionados en esta sección del artículo se analizan con más detalle en Mailhe (2016).

2 Cabe aclarar que las revistas porteñas aquí consideradas relevan solo casos vinculados a las instituciones médicas y penales más modernas, principalmente de Buenos Aires y en menor medida de las ciudades de Córdoba y Rosario. El resto del país permanece "fuera de foco". Ese "porteñocentrismo" resulta sintomático: al visibilizar patologías modernas -y en general, vinculadas a la inmigración europea-, las publicaciones difunden indirectamente la imagen de una europeización exitosa de la Argentina.

$\underline{3}$ Sobre este tema, en el largo proceso argentino de fines del siglo XVIII a inicios del XX, ver Di Liscia (2002).

4 Así por ejemplo, el facultativo señala que "la mayor parte de los insanos pertenecientes a la real Irlanda son afectos de monomanía religiosa” (Meléndez 1883: 173).

$\underline{5}$ Aquí el autor apela sutilmente al tópico decadentista del papel enfermante de la civilización.

$\underline{6}$ Incluso, Meléndez no desperdicia la ocasión de insistir en el peligro que representan especialmente los clérigos irlandeses (Meléndez 1885: 200).

$\underline{7}$ Así por ejemplo, menciona el caso de la "Hermana María”, analizado en "Curanderismo y locura”, como modelo de la patologización religiosa, además de remitir, a lo largo del ensayo, a otros artículos también editados en Archivos... (como la galería de "invertidos” estudiados por Francisco De Veyga).

8 La categoría de “mala vida” permite ampliar el alcance de la criminología para incluir estados pre-delictuales de cierta peligrosidad social. Sobre la historia del concepto ver Campos Marín (2009).

$\underline{9}$ Ver Di Liscia (2002).

10 Para Facio, estos son los casos de patología social que exigen una urgente persecución por ejercicio ilegal de la medicina (La Semana Médica 1910: 610).

11 Di Liscia (2002) enmarca este milenarismo en el contexto mayor de otros milenarismos latinoamericanos, como Canudos o la rebelión del Padre Cícero. Claramente, no se trata de movimientos revolucionarios, sino de respuestas de resistencia a las transformaciones modernizadoras. Palermo (1978) advierte que este levantamiento está vinculado al alzamiento del Malón Grande, dirigido por Calfucurá en marzo de 1872, y sobre el cual ya hay rumores en la zona desde fines de 1871.

12 Los periódicos de 1870 tienden a asociar gauchos alzados y malones salvajes, y a condenar el hecho como resultado de la sugestión colectiva por parte de un líder negativo (aun antes de la sistematización teórica de la Psychologie des foules de Le Bon). Sobre los discursos de la época ver Nario (1956).

13 Un buen ejemplo de esta patologización del mundo popular se encuentra en el artículo "Neurosis de los 
atorrantes” (editada en la Revista Médico-Quirúrgica en 1884): allí Meléndez afirma la condición neuropática de los marginales sociales que sobreviven en situación de calle, en su mayoría víctimas del alcohol.

14 Esa circulación se espeja por ejemplo en el caso del médico, alquimista y astrólogo Paracelso que, según recuerda Granada (1947: 279), reconocía que sus conocimientos médicos provenían del vulgo, obtenidos entre curanderos y pastores, logrando hacer desde allí contribuciones objetivas a la medicina. Es probable que a Granada le interesara especialmente esta figura por su cruce entre modernización médica y arcaísmo alquímicoastrológico.

15 Así por ejemplo, analiza el caso reciente de una joven mestiza en Uruguay, que se manifiesta como (supuestamente) poseída por el demonio: Granada detalla los fenómenos paranormales que el pueblo cree ver y oír en la casa, mostrándolos como resultado de la sugestión colectiva, al tiempo que frente a los esfuerzos inútiles del exorcista popular, defiende la eficacia del médico convocado "por consejo de personas sensatas" (Granada 1947: 316).

16 Poniendo en evidencia una concepción elitista de la dinámica cultural y del folclore, Korn cita in extenso un antiguo conjuro caldeo, para probar la degradación de las antiguas creencias, que ahora sobreviven bajo formas espurias muy simplificadas. Y para demostrar -desde una posición etnocéntrica- esa supervivencia de paradigmas culturales "asincrónicos" e "incompatibles", recuerda el caso (conocido durante su propio ejercicio profesional) de una paciente que, internada en el hospital, manda traer un gallo para entregárselo al médico como ofrenda ritual, a fin de propiciar su curación.

17 Ver por ejemplo Granada (1947: 337-338).

18 Recogiendo los “desperdicios dejados en el campo de la observación por la pluma grave del historiador y del sociólogo” (Granada 1947: 12).

19 Pues, citando de manera ambigua Le Diable et l’Occultisme de Papús, advierte que "el legítimo sacerdote del diablo en la tierra es el materialista, el ateo, para quien las fuerzas espirituales no son otra cosa que el resultado de una debilidad cerebral, que conduce al misticismo" (Granada 1947: 318).

$\underline{20}$ En este sentido, Granada opone "nosotros” y “ellos”, reforzando las fracturas culturales, de clase y de género. Dice que no cree en esas supersticiones que son propias de mestizos, mulatos, indios y mujeres (es decir, de la población más proclive a la irracionalidad).

$\underline{21}$ Para Granada, el realismo "es un sistema pernicioso" sobre todo en los países en que "la literatura está en la infancia” (Granada 1947: 14), porque crea el hábito de no despegarse del plano material, perdiendo de vista la necesidad de trascendencia.

$\underline{22}$ Rojas piensa un ordenamiento triádico y ascensional de los saberes, de la ciencia al arte y de ésta a la religión como superación de ambas.

$\underline{23}$ Así por ejemplo, el brasileño Mário de Andrade, en textos como Música de feitiçaria no Brasil (de 1933), cruza las exploraciones vanguardista y etnográfica de candomblés, macumbas y catimbós, creando una valoración contradictoria (de rechazo racional y, al mismo tiempo, de empatía afectiva, e incluso de fascinación estética) ante la riqueza del rito religioso (en un procedimiento común al desplegado en el capítulo "Macumba" de su novela Macunaíma de 1928). Sin embargo, en términos antropológicos, esa mediación cultural no deja de implicar una tergiversación de los significados originarios de las prácticas populares.

24 Para Granada, el positivismo "ha tratado de incrustarse, y no sin eficacia, en el seno de las sociedades americanas” (Granada 1947: 13).

$\underline{25}$ Si bien advierte que "en las supersticiones se transparenta de una manera ingenua y característica la psicología de las colectividades humanas” (Korn 1911: 288), también señala que, al menos en el caso de Argentina, las supersticiones no permiten aprehender una especificidad nacional, dado el alto mestizaje de nativos y extranjeros, 
quienes “abrigan en el fondo las mismas supersticiones” (Korn 1911: 291). Es probable que en este tipo de juicios pese su propio origen (ya que, como descendiente de padres inmigrantes, se forma en un hogar marcado por la cultura germánica).

$\underline{26}$ Rojas apela a un esoterismo mestizo, basándose teóricamente en Les Grands Initiés del escritor y musicólogo Edouard Schuré. Allí Schuré estudia la iniciación esotérica de diversas figuras (Rama, Krishna, Pitágoras, Orfeo, Jesús y Buda entre otros), advirtiendo que todos tendrían un conocimiento esotérico común.

27 Así por ejemplo, afirma que es el mismo concepto de “diablo" el que se manifiesta en el vulgo ibérico y entre los indios de la Patagonia, del Chaco o de la zona andina. Entre los numerosos ejemplos que refuerzan este reduccionismo eurocéntrico, cabe agregar la imposición, por parte de Granada, de nombres exógenos para la fauna local (como las reiteradas referencias al tigre en América del Sur) o el desconocimiento de las plantas alucinógenas locales.

$\underline{28}$ Así por ejemplo, cuando lista las denominaciones del diablo en los sectores populares americanos (como el Zupay en Perú, Cemí en Santo Domingo o Mandinga entre los negros), pierde de vista la diferencia cultural entre las diversas cosmovisiones, el impacto de la dominación colonial y el sincretismo como respuesta de resistencia adaptativa.

$\underline{29}$ La cultura popular rioplatense se percibe solo a través de la lente eurocéntrica de los procesos inquisitoriales y de las fuentes coloniales, más allá de algunas referencias aisladas a las obras de Santos Vega, Estanislao del Campo o José Hernández, o de algunos ejemplos locales contemporáneos (como el del Tata Dios de Tandil, mencionado en Granada 1947: 264).

$\underline{30}$ Aunque no cita una fuente específica de Ambrosetti, es probable que Korn se refiera a El Diablo indígena. Supersticiones y leyendas en la Argentina, editado el mismo año en que Korn publica su ensayo.

31 Además, es probable que la ausencia de referencias directas al mundo colonial y la falta de otras referencias eruditas provengan de la distancia que parece mantener el autor (psiquiatra y filósofo) con la materia folclórica. Incluso, errando el nombre del autor de la Reseña..., Korn se refiere a éste como "David” Granada.

32 En efecto, Granada coincide con el enfoque de José Ingenieros en "La vanidad criminal”, en donde advierte sobre los peligros de la lectura popular de la literatura gauchesca que transforma en héroes a este tipo de marginales. También Gómez en La mala vida... reitera esta crítica.

\section{BIBLIOGRAFÍA}

Acuña, N. y J. Alba Carreras (1903). “Curanderismo y locura”, en Archivos de psiquiatría, criminología y ciencias afines, v. II, pp. 649-653.

Andrade, Mário de (1983). Música de feitiçaria no Brasil, Obras completas, Belo Horizonte, Itatiaia / Brasília, v. 12.

Angenot, Marc (2010). “El discurso social”, El discurso social, Buenos Aires, Siglo XXI, pp. 21-94.

Campos Marín, Ricardo (2009). "Los fronterizos del delito”, Miranda, Marisa - Girón Sierra, Álvaro (orgs.). Cuerpo, biopolítica y control social, Buenos Aires, Siglo XXI, pp. 54-67.

Di Liscia, Silvia (2002). Saberes, terapias y prácticas médicas en Argentina (1750-1910), Madrid, Consejo Superior de Investigaciones Científicas.

Facio, Leónidas J. (1910). "Factores científicos del charlatanismo”, La Semana Médica, 28 de abril, a. XVII, n 17, pp. 605-610. 
Franceschi (1885). “El curanderismo en la provincia de Buenos Aires”, Revista Médico-Quirúrgica, a. XXI, n²2, pp. 347-8.

Gómez, Eusebio (1908). La mala vida en Buenos Aires, Buenos Aires, Juan Roldán.

Granada, Daniel (1947) [Reseña histórico-descriptiva de antiguas y modernas supersticiones del Río de la Plata, 1896]. Supersticiones del Río de La Plata, Buenos Aires, Kraft.

Ingenieros, José (1907). “La vanidad criminal”, Archivos de psiquiatría, criminología y ciencias afines, v. VI, pp. 161-170.

Korn, Alejandro (1911). “Las supersticiones nacionales”, Anales de psicología, v. II, pp. 288-297.

Mailhe, Alejandra (2014). "El archivo de Archivos. Un latinoamericanismo eurocéntrico la psiquiatría y la criminología de principios del siglo XX”, Vária História, v. 30, n 54, pp. 655-678.

Mailhe, Alejandra (2016). Archivos de psiquiatría y criminología (1902-1912): concepciones del sujeto femenino $y$ de la alteridad social. "Biblioteca Orbis Tertius", La Plata, FaHCE, UNLP. Recuperado de bibliotecaorbistertius.fahce.unlp.edu.ar/11.\%20Mailhe.pdf.

Meléndez, Lucio (1883). "Monomanía religiosa. Ideas impulsivas. Suicidio”, Revista Médico-Quirúrgica, 8 de septiembre, a. XX, nº 11, pp. 173-175.

Meléndez, Lucio (1885). "Melancolía apática; ideas religiosas; fenómenos histéricos”, Revista MédicoQuirúrgica, 8 de octubre, a. XXIII, n 13, pp. 197-200.

Meléndez, Lucio (1884). “Neurosis de los atorrantes” Revista Médico-Quirúrgica, 8 de julio, a. XXI, nº 7, pp. 104-106.

Meléndez, Lucio (1884). “Los locos en la Capital”, Revista Médico-Quirúrgica, 8 de julio, a. XXI, n 7, pp. 102104.

Nario, Hugo (1956). Tata Dios. El Mesías de la última montonera, Buenos Aires, Plus Ultra.

Palermo, Miguel Ángel (1978). “El fin del mundo en Tandil”, Punto de vista, nº 1, pp. 8-13. 